\title{
D-Cycloserine into the BLA reverses the impairing effects of exposure to stress on the extinction of contextual fear, but not conditioned taste aversion
}

\author{
Irit Akirav, ${ }^{1}$ Amir Segev, ${ }^{1}$ Helen Motanis, ${ }^{2}$ and Mouna Maroun ${ }^{2,3}$ \\ ${ }^{1}$ Department of Psychology, University of Haifa, Haifa 31905, Israel; ${ }^{2}$ Department of Neurobiology and Ethology, Faculty of \\ Sciences and Science Education, University of Haifa, Haifa 31905, Israel
}

\begin{abstract}
We investigated whether the $N$-methyl-D-aspartate (NMDA) receptor partial agonist D-cycloserine (DCS, $20 \mu \mathrm{g} / \mathrm{side}$ ) microinfused into the basolateral amygdala (BLA) would reverse stress-induced impairment of extinction in two aversive learning paradigms: contextual fear conditioning and conditioned taste aversion (CTA). We found that DCS in the BLA show differential involvement in the extinction of these two paradigms and in its modulation of stress-induced impairment of extinction. This may suggest that the dysfunctional extinction of fear and taste aversion following exposure to a stressful experience may be modulated by different mechanisms.
\end{abstract}

Converging evidence suggest that dysfunctional fear extinction plays an important role in the development of clinical symptoms such as re-experiencing of trauma in post-traumatic stress disorder (PTSD) (Charney et al. 1993; Cammarota et al. 2007; Lutz 2007). There are several reports from animal studies suggesting that exposure to stressful experiences might disrupt the extinction of fear. We recently showed that $30 \mathrm{~min}$ of exposure to the elevated platform stressor disrupts the extinction of auditory and contextual fear conditioning (Akirav and Maroun 2007) and the extinction of inhibitory avoidance (Ganon-Elazar and Akirav 2009). Others have reported that stress reduces cued fear extinction (Shumake et al. 2005; Izquierdo et al. 2006; Maren and Chang 2006) or impairs its recall (Maren and Chang 2006; Miracle et al. 2006; Garcia et al. 2007). On the other hand, exposure to stress facilitates the initial fear learning, thus further enhancing the fear response (Shors et al. 1992; Cordero et al. 2003; Ganon-Elazar and Akirav 2009).

The amygdala modulates the effects of stress on learning and memory (Kim and Diamond 2002; McGaugh 2004) but also plays an important role in emotional conditioning and its experimental extinction (Davis 1992; Falls et al. 1992; LeDoux 1993; McGaugh et al. 1993; Maren 1999; Nader et al. 2000; Lu et al. 2001). $\mathrm{N}$-methyl-D-aspartate (NMDA) receptors in the basolateral amygdala (BLA) play an important role in fear extinction (Falls et al. 1992; Walker et al. 2002). Administration of the partial NMDA receptor agonist D-cycloserine (DCS) facilitates extinction of conditioned fear (Walker et al. 2002; Ledgerwood et al. 2003; Ressler et al. 2004; Yang and $\mathrm{Lu} 2005$ ) and alleviates impaired fear extinction in a rat model for PTSD (Yamamoto et al. 2008).

Here we aimed to compare the involvement of NMDA receptors in the BLA in stress-induced dysfunctional extinction learning in two aversive learning paradigms: a task that is biologically meaningful for rodents, but is not fear-related (i.e., conditioned taste aversion [CTA]) and a fear-related paradigm (i.e., contextual fear conditioning). We found that NMDA receptors in the BLA show differential involvement in the extinction of these

\footnotetext{
${ }^{3}$ Corresponding author.

E-mail mmaroun@psy.haifa.ac.il and mouna.maroun@gmail.com; fax 972-4-8249157.

Article is online at http://www.learnmem.org/cgi/doi/10.1101//m.1565109.
}

two paradigms and in the modulation of stress-induced impairment of extinction.

The subjects were male Wistar rats ( $60 \mathrm{~d}$ old, $250-300 \mathrm{~g}$ ), caged individually at $22^{\circ} \mathrm{C} \pm 2^{\circ} \mathrm{C}$ under 12 -h light/12-h dark cycles. All tests were performed between 10 a.m. and 4 p.m. The experiments were approved by the University of Haifa Ethics and Animal Care Committee, and adequate measures were taken to minimize pain or discomfort in accordance with the guidelines laid down by the NIH in the US regarding the care and use of animals for experimental procedures.

Rats in all of the groups were implanted bilaterally with a guide stainless cannula (23 gauge) aimed at the BLA (anteroposterior, $-3 \mathrm{~mm}$ relative to bregma; lateral, $\pm 5 \mathrm{~mm}$; ventral, -6.7 $\mathrm{mm})$. The cannulae were positioned in place with acrylic dental cement and secured by two skull screws. A stylus was placed in the guide cannula to prevent clogging. Animals were allowed $1 \mathrm{wk}$ to recuperate.

For contextual fear conditioning, rats were placed in a conditioning chamber with floor grids and transparent Plexiglas walls. For conditioning, rats received three $0.5 \mathrm{~mA}$, 1-sec footshocks delivered to the floor bars. The three shocks were administered 90 , 210, and 330 sec after animals were placed in the conditioning chamber. After each conditioning session the shock grids and the Plexiglas walls were cleaned with odorous clean wipes. For extinction, rats were submitted to a nonreinforced test trial every $24 \mathrm{~h}$ for $3 \mathrm{~d}$ (T1-T3), beginning 24 -h post-conditioning. Rats were placed in the conditioning chamber and were allowed to explore for $5 \mathrm{~min}$, and the duration of freezing was measured every minute, with no footshock. The video images were analyzed by a computer (Dell OptiPlex GXpro) equipped with an analysis program and a macroprogram (P. Schmid, Behavioral Neurobiology Laboratory, Swiss Federal Institute of Technology Zurich). The percentage of changed pixels between two adjacent 1-sec images was calculated and if the percentage of change in images was $<0.05 \%$, the behavior of the rat was scored as "freezing" for the respective later second. Freezing was defined as the absence of all movement except for respiration (Blanchard and Blanchard 1972; Kim et al. 1992).

For CTA, saccharin $(0.1 \% \mathrm{w} / \mathrm{v})$ was used as the conditioned stimulus (CS) and lithium chloride ( $\mathrm{LiCl}, 0.15 \mathrm{M}, 2 \%$ body weight, intraperitoneally [i.p.]) as the malaise-inducing agent. Rats were pretrained to get their water ratio once a day for $10 \mathrm{~min}$ from two 
pipettes, each containing $10 \mathrm{~mL}$ of tap water. On the conditioning day, they were allowed to drink the saccharin solution instead of water for $10 \mathrm{~min}$, and $40 \mathrm{~min}$ after the offset of the drinking period they were injected with $\mathrm{LiCl}$ i.p. For the next $2 \mathrm{~d}$, the rats were presented daily for $10 \mathrm{~min}$ with two pipettes, each containing 10 $\mathrm{mL}$ of tap water. Three days after training, a 10-min multiplechoice test (consisting of three water pipettes and three saccharin pipettes, each containing $5 \mathrm{~mL}$ ) was performed to determine the acquired aversion. To measure CTA extinction, the test was repeated for four successive days. The conditioned aversion is presented as an aversion index, defined as $\mathrm{mL}$ of water/( $\mathrm{mL}$ of water $+\mathrm{mL}$ of saccharin) $\times 100$, consumed in the test; hence, 50 indicates equal preference.

Immediately following the first nonreinforced test trial of contextual fear or CTA, rats were exposed to the behavioral stressor. They were microinfused with vehicle and placed on an elevated platform (EP; $12 \times 12 \mathrm{~cm}$ ) for $30 \mathrm{~min}$ in a brightly lit room. Rats exhibited behavioral "freezing," that is, immobility for up to $10 \mathrm{~min}$, defecation, and urination (Maroun and Akirav 2008). During the first $10 \mathrm{~min}$ on the EP, freezing levels were measured manually by an observer blind to the drug treatment. The number of defecation and urination events was also recorded.

For microinfusion, the stylus was removed from the guide cannula, and a 28-gauge injection cannula, extending $1.0 \mathrm{~mm}$ from the tip of the guide cannula, was inserted. The injection cannula was connected via PE20 tubing to a Hamilton microsyringe driven by a microinfusion pump (CMA/100; Carnegie Medicin). Microinfusion was performed bilaterally in a $0.5-\mu \mathrm{L}$ volume per hemisphere delivered over $1 \mathrm{~min}$. The injection cannula was left in position before withdrawal for an additional $1 \mathrm{~min}$ to minimize dragging of the injected liquid along the injection tract. Although a small volume of infusion $(0.5 \mu \mathrm{L})$ was used, the possibility of injection spreading to other structures cannot be completely ruled out.

We microinfused the NMDA receptor partial agonist DCS (20 $\mu \mathrm{g} / 0.5 \mu \mathrm{L}$; Sigma) or saline into the BLA. DCS was dissolved in physiological saline, which was also used as vehicle. The DCS dose was based on our previous work (Akirav 2007).

Thirty minutes following microinfusion or immediately following exposure to the EP stress, rats were examined in the open-field test for locomotion and anxiety. A video image of the entire open field was displayed on a TV monitor, and the movements of the rat, which was initially placed in a corner of the field, were manually recorded and analyzed to measure motor activity over a period of $5 \mathrm{~min}$. Recordings were made of the time the rat spent in the central and the peripheral squares, the number of instances of rearing, and the total distance covered. The open-field arena was thoroughly cleaned between each trial.

At the completion of the behavioral experiments animals were deeply anesthetized and microinfused into the BLA with 0.5 $\mu \mathrm{L}$ of India ink. Frozen brain slices $(60 \mu \mathrm{m})$ were examined under a light microscope following Nissl staining to verify the cannula location (Fig. 1).

For contextual fear conditioning, four groups of rats were conditioned, and on the next day they were exposed to the first nonreinforced trial, i.e., with no shocks (T1). One-way ANOVA revealed that the groups did not differ in their freezing levels on T1 $\left(F_{(3,37)}<1\right.$, NS), indicating similar freezing levels $24 \mathrm{~h}$ following conditioning.

Immediately after $\mathrm{T} 1$, rats were microinfused with vehicle (Vehicle, $n=14$ ), or microinfused with vehicle and placed on the EP for $30 \mathrm{~min}$ (EP, $n=10$ ), or microinfused with DCS and immediately afterward placed on the EP for $30 \mathrm{~min}$ (DCS + EP, $n=9$ ), or microinfused with DCS without exposure to the stressor $(\mathrm{DCS}, n=8$ ) (Fig. 2A). Repeated-measures ANOVA (group $\times$ day $[4 \times$ 2]) revealed a significant difference between the groups in terms of

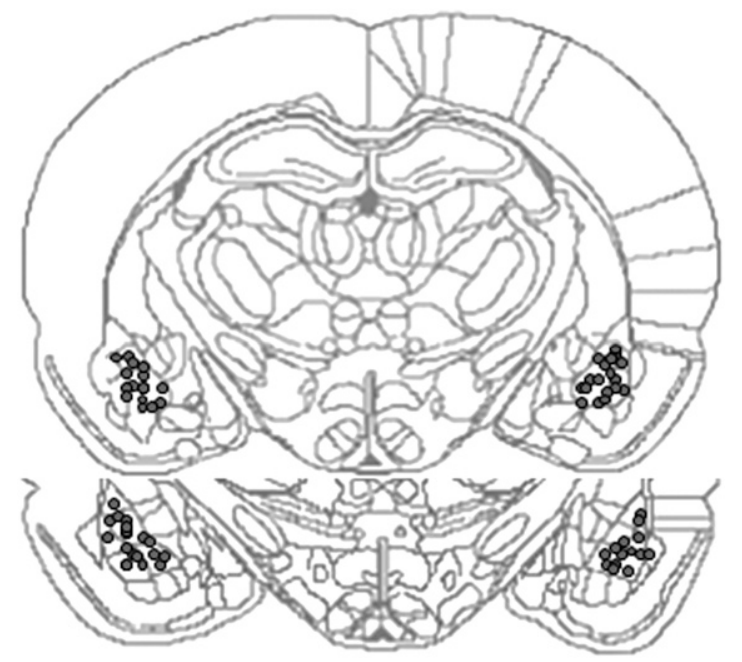

Figure 1. Schematic drawing of representative cannulae tip positions in the basolateral amygdala (BLA). Shown is a coronal view at position 3.14 and $3.30 \mathrm{~mm}$ anterior to bregma. (Adapted from Paxinos and Watson [1986] and reprinted with permission from Elsevier (c)1986.)

their freezing levels $\left(F_{(3,37)}=5.28 ; P=0.004\right)$, and a significant effect on days $\left(F_{(1,37)}=10.53 ; P=0.002\right)$, with no significant interaction effect $\left(F_{(3,37)}<1, \mathrm{NS}\right)$.

One-way ANOVA applied for the different post-treatment days showed that the groups significantly differed in their freezing levels on T2 $\left(F_{(3,37)}=5.71 ; P=0.003\right)$, but not on $\mathrm{T} 3\left(F_{(3,37)}=2.5\right.$, NS). Post-hoc analysis for the differences between the groups on T2 revealed that the EP group showed significantly increased freezing levels compared with all the other groups $(P<0.05)$. Thus, exposure to the EP stressor following the first extinction session disrupted extinction of contextual fear conditioning. Additionally, rats microinfused with DCS (with no EP exposure) showed significantly reduced freezing levels compared with the vehicle group (DCS: $P=0.049$ ). Thus, merely microinfusing DCS into the BLA following T1 facilitated extinction of contextual fear. Microinfusing DCS into the BLA before exposure to the EP reversed the effects of the stressor on extinction, as no significant differences were observed between the vehicle and the DCS + EP groups.

Next, we examined whether DCS altered the stress response to the EP exposure. First, we compared freezing behavior, defecation, and urination during the first $10 \mathrm{~min}$ on the EP in rats microinfused with vehicle or DCS into the BLA ( $n=6$ each). The results indicate that there were no significant differences between the groups in their freezing levels $\left(t_{(10)}<1\right.$, NS) or the number of urination and defecation events $\left(t_{(10)}<1\right.$, NS) (data not shown). Second, rats microinfused with vehicle into the BLA (Vehicle, $n=$ 9) or microinfused with vehicle and placed on the EP for $30 \mathrm{~min}$ (EP, $n=7$ ), or microinfused with DCS (DCS, $n=6$ ), or microinfused with DCS and immediately afterward placed on the EP for $30 \mathrm{~min}$ (DCS + EP, $n=6)$, were tested in the open field. One-way ANOVA revealed a significant difference between the groups in the time spent in the center $\left(F_{(3,27)}=3.21, P=0.041\right)$ and the number of rearing events $\left(F_{(3,27)}=3.54, P=0.03\right)$ (Table 1). Post-hoc comparisons revealed that the vehicle group spent significantly more time in the center of the arena compared with the other groups (EP: $P=0.039$; DCS: $P=0.015$; DCS + EP: $P=0.025$ ) and reared significantly more times than the EP $(P=0.009)$ and the DCS + EP $(P=0.016)$ groups. Rearing behavior characterizes individual differences in reactivity to novelty and, thus, more frequent rearing may indicate greater novelty-seeking behavior 
A

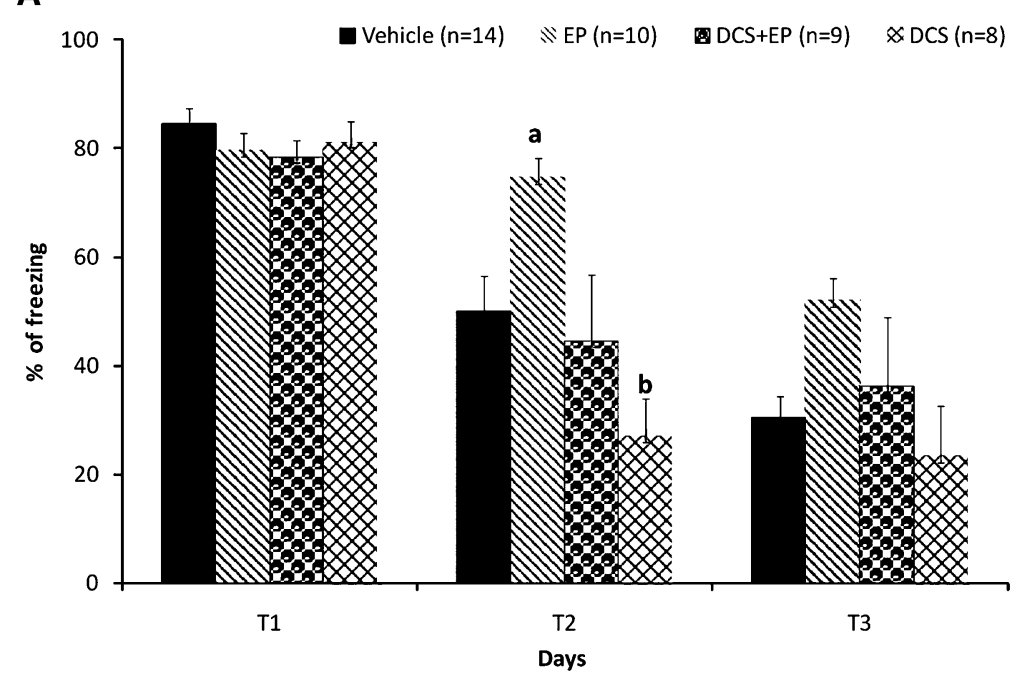

B

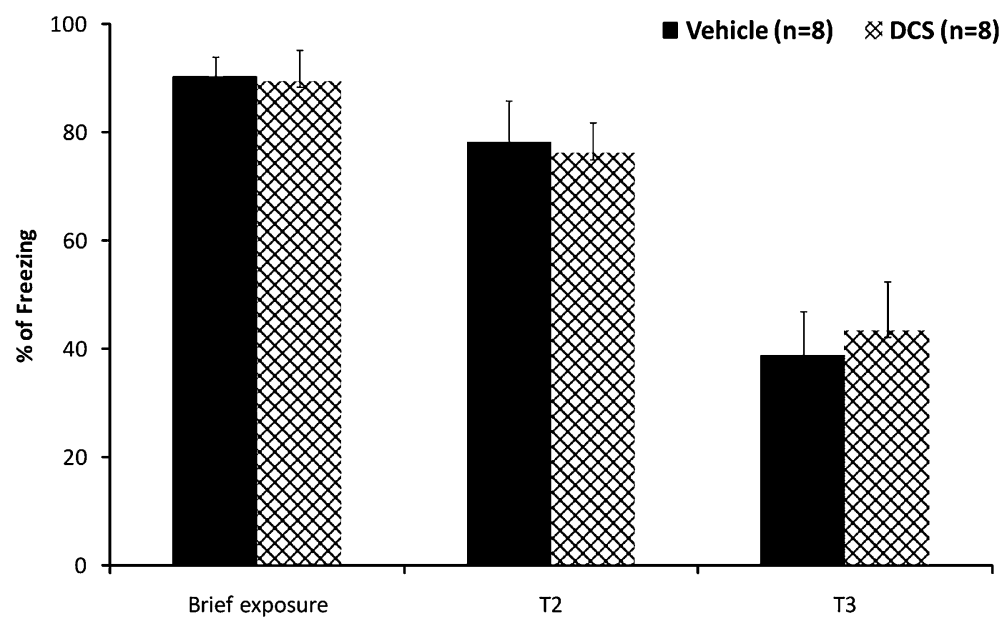

Figure 2. Microinfusing DCS into the BLA reversed the impairing effect of exposure to stress on extinction of contextual fear conditioning $(A)$. Exposure to the EP stressor significantly increased freezing levels on T2 compared with all of the groups $(a, P<0.05)$. Microinfusing DCS into the BLA after T1 decreased freezing levels on T2 compared with the vehicle group $(b, P<0.05)$. (B) Microinfusing DCS into the BLA following brief exposure to the context did not affect extinction of contextual fear conditioning.

(i.e., less anxiety) (Thiel et al. 1999). There were no significant differences in time spent in the periphery $\left(F_{(3,27)}<1\right.$, NS) or the distance covered $\left(F_{(3,27)}<1, \mathrm{NS}\right)$. No significant difference between the EP and DCS + EP groups was found in any of the parameters measured, suggesting that DCS did not alter the response to stress as measured in the open-field test.

It could be argued that DCS facilitated extinction through impairment of retention performance rather than facilitation of extinction consolidation. In order to exclude this possibility, rats were fear conditioned as described above, and on the next day they were exposed to the conditioning context for a very brief exposure (i.e., $2 \mathrm{~min}$ ). Immediately after the brief exposure to the context on and anxiety in the open-field test

${ }^{\text {a }} P<0.05$.

${ }^{\mathrm{b}} P<0.01$

${ }^{c} P<0.05$.
T1, rats were microinfused either with vehicle (Vehicle, $n=8$ ) or DCS (DCS, $n=$ 8). $T$-test revealed that the groups did not differ in their freezing levels on T1, T2, or T3, indicating similar freezing levels following conditioning (Fig. 2B). This suggests that DCS microinfused into the BLA did not impair retention performance.

For CTA, four groups of rats were conditioned, and after $3 \mathrm{~d}$ they were exposed to the first nonreinforced trial, i.e., with no $\mathrm{LiCl}$ (T1). One-way ANOVA revealed that the groups did not differ in their aversion index on T1, indicating similar aversion to saccharine $\left(F_{(3,42)}<\right.$ 1 , NS). Immediately after $\mathrm{T} 1$, rats were microinfused either with vehicle (Vehicle, $n=11$ ), or microinfused with vehicle and placed on the EP for $30 \mathrm{~min}$ (EP, $n=$ 13), or microinfused with DCS and immediately afterward placed on the EP for 30 min (DCS + EP, $n=13$ ), or microinfused with DCS without exposure to the stressor (DCS, $n=7$ ) (Fig. 3).

Repeated-measures ANOVA (group $\times$ day $[4 \times 3]$ ) did not show a significant difference between the groups in terms of their aversion index $\left(F_{(3,40)}=1.54 ; \mathrm{NS}\right)$, or interaction between group and day $\left(F_{(3,40)}=1.39, \mathrm{NS}\right)$, but a significant effect on days $\left(F_{(1,42)}=83.32, P<0.0001\right)$, indicating that the four groups extinguished similarly over the test days.

One-way ANOVA applied for the different post-treatment days showed that the groups significantly differed in their aversion index on T2 $\left(F_{(3,40)}=3.99\right.$, $P=0.014)$, but not on $\mathrm{T} 3\left(F_{(3,40)}=1.06\right.$, NS) or T4 $\left(F_{(3,40)}=1.13\right.$, NS).

Post-hoc analysis for T2 revealed that the Vehicle group showed reduced aversion compared with the EP $(P=$ $0.001)$, and the DCS + EP $(P=0.04)$ groups. There was no significant difference between the Vehicle and the DCS group. Thus, exposure to the EP stressor following the first extinction session disrupted extinction of CTA. Microinfusing DCS into the BLA had no effect on extinction kinetics and DCS failed to reverse the impairing effects of the stressor on CTA extinction.

Table 1. The effects of exposure to stress and DCS microinfused into the BLA on locomotion

\begin{tabular}{lcccc}
\hline & Vehicle, $\boldsymbol{n}=\mathbf{9}$ & EP, $\boldsymbol{n}=\mathbf{7}$ & DCS, $\boldsymbol{n}=\mathbf{6}$ & DCS + EP, $\boldsymbol{n}=\mathbf{6}$ \\
\hline Distance covered $(\mathrm{cm})$ & $854.44 \pm 119.98$ & $834.28 \pm 102.28$ & $998 \pm 193.06$ & $748 \pm 115.75$ \\
Time in center $(\mathrm{sec})$ & $12.44 \pm 3.7^{\mathrm{a}}$ & $4.73 \pm 0.77$ & $2.73 \pm 0.83$ & $3.6 \pm 2.15$ \\
Time in periphery $(\mathrm{sec})$ & $219.77 \pm 12.54$ & $206.28 \pm 8.2$ & $198.8 \pm 23.2$ & $188.4 \pm 7.2^{\mathrm{b}}$ \\
$\begin{array}{l}\text { Number of rearing } \\
\text { events }\end{array}$ & $21.55 \pm 1.9$ & $13 \pm 0.65^{\mathrm{b}}$ & $18 \pm 3.33$ & $13.4 \pm 2.89^{\mathrm{c}}$ \\
& & & & \\
\hline
\end{tabular}

Rats microinfused with vehicle into the BLA spent more time in the center compared with all the groups and showed increased rearing compared with the EP and DCS groups. 
- Vehicle $(n=11) \quad \mathbb{N E P}(n=13) \quad$ DCS+EP $(n=13) \quad \approx D C S(n=7)$

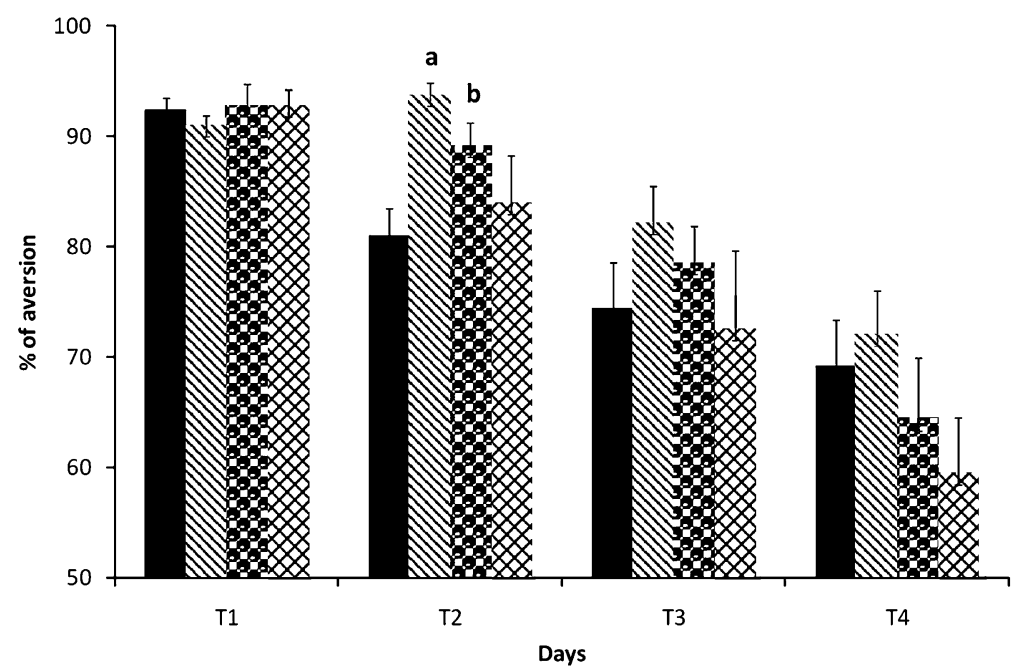

Figure 3. Microinfusing DCS into the BLA did not reverse the impairing effect of exposure to stress on extinction of CTA. Exposure to the EP stressor or microinfusing DCS into the BLA and then placing the rats on the EP resulted in enhanced aversion compared with the vehicle group on T2 $(a, P<0.01 ; b, P<$ $0.05)$.

The main finding of this study is that stress induces marked impairment of contextual fear and CTA extinction and that intraBLA infusion of the NMDA receptor partial agonist DCS reverses the impairing effects of stress on extinction of conditioned fear, but not on the extinction of conditioned taste. Furthermore, DCS in the BLA facilitates the extinction of contextual fear with no effect on the extinction of CTA.

Although we found that stress can disrupt the extinction of the association between a novel taste and visceral malaise as well as an association that is based on fear, extinction is differentially sensitive to DCS microinfused into the BLA. This drug shows differential involvement in the extinction of the two paradigms and in its modulation of stress-induced impairment of extinction. This may suggest that the dysfunctional extinction of fear and taste aversion following exposure to a stressful experience may be modulated by different mechanisms (e.g., different brain regions or different neuromodulators).

Our results are in agreement with previous studies in which DCS administration enhanced the extinction of conditioned fear (Walker et al. 2002; Ledgerwood et al. 2003) and facilitated fear extinction in patients with anxiety disorders (Ressler et al. 2004; Hofmann et al. 2006). Furthermore, we have recently found that intra-BLA infusion of DCS together with $\mathrm{GABA}_{\mathrm{A}}$ agonist muscimol infusion reversed the blocking effects of muscimol on CTA extinction, yet DCS had no effect on CTA extinction by itself (Akirav 2007), hence, further confirming the differential role of DCS in the BLA in extinction of fear conditioning as compared with extinction of CTA.

There are human studies suggesting that using acute DCS with exposure therapy enhances fear extinction (Ressler et al. 2004; Hofmann et al. 2006), whereas DCS with no exposure therapy is not effective (Heresco-Levy et al. 2002). In support, here we find that whereas rats microinfused with DCS following a brief exposure to the context do not show enhanced extinction, DCS microinfused into the BLA following a longer exposure period with no shock, significantly facilitated fear extinction.

The microinfusion of DCS into the BLA before exposure to the elevated platform stress did not alter the different behavioral measures in the open-field test and the physiological measures with that aversive event (e.g., the context as well as exposure to a stressful event). DCS had no effect on extinction or on stress-induced disruption of CTA, which may limit the generalization effect of DCS to fear extinction.

The mechanism underlying how DCS facilitates fear extinction remains to be determined. Yet, our results suggest that the mechanisms underlying fear extinction and aversion extinction are different (e.g., based on different brain areas or different neuromodulators). We also give preclinical support to the suggestion that DCS could represent a therapeutic target for the treatment of diseases associated with dysfunctional extinction of fear, such as PTSD and phobia, but should not be necessarily generalized to all forms of aversive associations.

\section{Acknowledgments}

We acknowledge support by the Israel Science Foundation (ISF; grant no. 469/07) to M.M. We thank Professor Joram Feldon from the Laboratory of Behavioral Neurobiology, Swiss Federal Institute of Technology Zurich (ETH), Switzerland, for his generous help with the automated freezing system.

\section{References}

Akirav I. 2007. NMDA partial agonist reverses blocking of extinction of aversive memory by $\mathrm{GABA}_{\mathrm{A}}$ agonist in the amygdala. Neuropsychopharmacology 32: $542-550$.

Akirav I, Maroun M. 2007. The role of the medial prefrontal cortexamygdala circuit in stress effects on the extinction of fear. Neural Plast 2007. doi: $10.1155 / 2007 / 30873$.

Blanchard DC, Blanchard RJ. 1972. Innate and conditioned reactions to threat in rats with amygdaloid lesions. J Comp Physiol Psychol 81: 281290.

Cammarota M, Bevilaqua LR, Vianna MR, Medina JH, Izquierdo I. 2007. The extinction of conditioned fear: Structural and molecular basis and therapeutic use. Rev Bras Psiquiatr 29: 80-85.

Charney DS, Deutch AY, Krystal JH, Southwick SM, Davis M. 1993. Psychobiologic mechanisms of posttraumatic stress disorder. Arch Gen Psychiatry 50: 295-305.

Cordero MI, Venero C, Kruyt ND, Sandi C. 2003. Prior exposure to a single stress session facilitates subsequent contextual fear conditioning in rats: Evidence for a role of corticosterone. Horm Behav 44: 338345 . 
Davis M. 1992. The role of the amygdala in fear and anxiety. Annu Rev Neurosci 15: 353-375.

Davis M, Ressler K, Rothbaum BO, Richardson R. 2006. Effects of D-cycloserine on extinction: Translation from preclinical to clinical work. Biol Psychiatry 60: 369-375.

Falls WA, Miserendino MJ, Davis M. 1992. Extinction of fear potentiated startle: Blockade by infusion of an NMDA antagonist into the amygdala J Neurosci 12: 854-863.

Ganon-Elazar E, Akirav I. 2009. Cannabinoid receptor activation in the basolateral amygdala blocks the effects of stress on the conditioning and extinction of inhibitory avoidance. J Neurosci 29: 11078-11088.

Garcia R, Spennato S, Nilsson-Todd L, Moreau JL, Deschaux O. 2007. Hippocampal low-frequency stimulation and chronic mild stress similarly disrupt fear extinction memory in rats. Neurobiol Learn Mem 89: $560-566$.

Heresco-Levy U, Kremer I, Javitt DC, Goichman R, Reshef A, Blanaru M, Cohen T. 2002. Pilot-controlled trial of D-cycloserine for the treatment of post-traumatic stress disorder. Int J Neuropsychopharmacol 5: 301307.

Hofmann SG, Pollack MH, Otto MW. 2006. Augmentation treatment of psychotherapy for anxiety disorders with D-cycloserine. CNS Drug Rev 12: $208-217$.

Izquierdo A, Wellman CL, Holmes A. 2006. Brief uncontrollable stress causes dendritic retraction in infralimbic cortex and resistance to fear extinction in mice. J Neurosci 6: 5733-5738.

Kim JJ, Diamond DM. 2002. The stressed hippocampus, synaptic plasticity and lost memories. Nat Rev Neurosci 3: 453-462.

Kim J, Fanselow MS, DeCola JP, Landeira-Fernandez J. 1992. Selective impairment of long-term but not short-term conditional fear by the $N$-methyl-D-aspartate antagonist APV. Behav Neurosci 106: 591-596.

Ledgerwood L, Richardson R, Cranney J. 2003. Effects of D-cycloserine on extinction of conditioned freezing. Behav Neurosci 117: 341-349.

Ledgerwood L, Richardson R, Cranney J. 2005. D-cycloserine facilitates extinction of learned fear: Effects on reacquisition and generalized extinction. Biol Psychiatry 57: 841-847.

LeDoux JE. 1993. Emotional memory: In search of systems and synapses. Ann N Y Acad Sci 17: 149-157.

Lu KT, Walker DL, Davis M. 2001. Mitogen-activated protein kinase cascade in the basolateral nucleus of amygdala is involved in extinction of fear-potentiated startle. J Neurosci 15: 1-5.

Lutz B. 2007. The endocannabinoid system and extinction learning. Mol Neurobiol 36: 92-101.

Maren S. 1999. Neurotoxic basolateral amygdala lesions impair learning and memory but not the performance of conditional fear in rats. $J$ Neurosci 1: 8696-8703.
Maren S, Chang CH. 2006. Recent fear is resistant to extinction. Proc Natl Acad Sci 21: 18020-18025.

Maroun M, Akirav I. 2008. Arousal and stress effects on consolidation and reconsolidation of recognition memory. Neuropychopharmacology 33 394-405.

McGaugh JL. 2004. The amygdala modulates the consolidation of memories of emotionally arousing experiences. Annu Rev Neurosci 27: 1-28.

McGaugh JL, Introini-Collison IB, Cahill LF, Castellano C, Dalmaz C, Parent MB, Williams CL. 1993. Neuromodulatory systems and memory storage: Role of the amygdala. Behav Brain Res 20: 81-90.

Miracle AD, Brace MF, Huyck KD, Singler SA, Wellman CL. 2006. Chronic stress impairs recall of extinction of conditioned fear. Neurobiol Learn Mem 85: 213-218.

Nader K, Schafe GE, LeDoux JE. 2000. The labile nature of consolidation theory. Nat Rev Neurosci 1: 216-219.

Paxinos G, Watson C. 1986. The rat brain in stereotaxic coordinates. Elsevier, Oxford, UK.

Ressler KJ, Rothbaum BO, Tannebaum L, Anderson P, Graap K, Zimand E, Hodges L, Davis M. 2004. Cognitive enhances as adjuncts to psychotherapy: Use of D-Cycloserine in phobics to facilitate extinction of fear. Arch Gen Psychiatry 61: 1136-1144.

Shors TJ, Weiss C, Richard F. 1992. Stress-induced facilitation of classical conditioning. Science 257: 537-539.

Shumake J, Barrett D, Gonzalez-Lima F. 2005. Behavioral characteristics of rats predisposed to learned helplessness: Reduced reward sensitivity, increased novelty seeking, and persistent fear memories. Behav Brain Res 164: 222-230.

Thiel CM, Müller CP, Huston JP, Schwarting RK. 1999. High versus low reactivity to a novel environment: Behavioural, pharmacological and neurochemical assessments. Neuroscience 93: 243-251.

Walker DL, Ressler KJ, Lu KT, Davis M. 2002. Facilitation of conditioned fear extinction by systemic administration or intra-amygdala infusions of D-cycloserine as assessed with fear-potentiated startle in rats. J Neurosci 22: 2343-2351.

Yamamoto S, Morinobu S, Fuchikami M, Kurata A, Kozuru T, Yamawaki S. 2008. Effects of single prolonged stress and D-cycloserine on contextual fear extinction and hippocampal NMDA receptor expression in a rat model of PTSD. Neuropsychopharmacology 33: 2108-2116.

Yang YL, Lu KT. 2005. Facilitation of conditioned fear extinction by $\mathrm{D}$-cycloserine is mediated by mitogen activated protein kinase and PI-3 kinase cascades and requires de novo protein synthesis in basolateral nucleus of amygdale. Neuroscience 134: 247-260.

Received July 30, 2009; accepted in revised form August 18, 2009. 


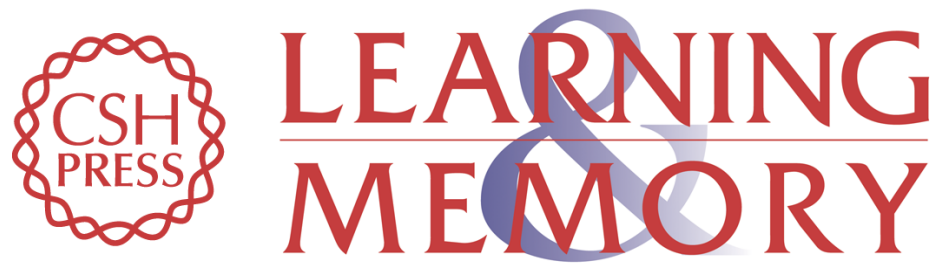

\section{D-Cycloserine into the BLA reverses the impairing effects of exposure to stress on the extinction of contextual fear, but not conditioned taste aversion}

Irit Akirav, Amir Segev, Helen Motanis, et al.

Learn. Mem. 2009, 16:

Access the most recent version at doi:10.1101/lm.1565109

References This article cites 35 articles, 4 of which can be accessed free at:

http://learnmem.cshlp.org/content/16/11/682.full.html\#ref-list-1

License

Email Alerting Receive free email alerts when new articles cite this article - sign up in the box at the Service top right corner of the article or click here. 